\title{
RESEÑA: INTELIGENCIA ARTIFICIAL Y BIENESTAR DE LAS JUVENTUDES EN AMÉRICA LATINA. LIONEL BROSSI, TOMÁS DODDS Y EZEQUIEL PASSERON, EDITORES ${ }^{1}$
}

\author{
YADIRA PALENZUELA FUNDORA ${ }^{2}$
}

A menos de un año de la publicación del texto Inteligencia Artificial y bienestar de las juventudes en América Latina ${ }^{3}$, la mayor parte del planeta quedó confinada por la pandemia del COVID-19. Ante esta situación, internet y las plataformas digitales devinieron en una alternativa clave para seguir funcionando en los diferentes planos de la vida. Las y los jóvenes de diversas latitudes, contextos y culturas, con acceso a las redes, aumentaron sus experiencias y tiempos de interacción en distintas plataformas digitales. De esta forma, también se incrementó su exposición a la Inteligencia Artificial (IA).

Por ello cobra relevancia la discusión que abre el texto que se analiza, el cual es reconocido en su prólogo por Ravalli y Cortesi como «la primera iniciativa colectiva que discute e indaga sobre la intersección entre el bienestar de la juventud y la IA con el foco en América Latina y con voces y miradas desde

\footnotetext{
${ }^{1}$ LOM ediciones, Santiago de Chile, 2019.

${ }^{2}$ Doctora en Psicología, Universidad de Chile. Psicóloga y Máster en Psicología Educativa, Universidad de La Habana, Cuba. Magíster en Análisis Sistémico Aplicado a la Sociedad, Universidad de Chile. Miembro Núcleo de Investigación y Acción en Juventudes de la Universidad de Chile y del GT Infancia y Juventudes de CLACSO. Correo electrónico: ypalenzuela@ug.uchile.cl
}

3 Se puede descargar de forma gratuita en: https://www.uchile.cl/publicaciones/171146/inteligencia-artificial-y-bienestar-dejuventudes-en-america-latina 
la propia región» (p. 13).

El libro forma parte de una iniciativa colaborativa apoyada por la red Conectados al Sur-Digitally Connected, el Instituto de Comunicación e Imagen (ICEI) de la Universidad de Chile, Faro Digital Argentina, el Núcleo Milenio para Mejorar la Salud Mental de Adolescentes y Jóvenes (Imhay), la Cátedra Latinoamericana de Narrativas Transmedias e ITS Rio. Sus 276 páginas están divididas en cinco grandes partes y cuenta con la participación de 46 autores/as latinoamericanos/asm de los cuales algunos comparten roles adicionales siendo editores de sección (9) y otros como editores generales (3).

La obra aborda, desde diferentes disciplinas, enfoques epistemológicos, teóricos y metodológicos, las principales oportunidades y desafíos que enfrentan las juventudes en relación con la educación, la salud, el futuro del trabajo, la información, el bienestar, la privacidad, seguridad y la protección de sus datos en la red. Su abordaje se realiza desde una perspectiva situada y crítica, reflexionando sobre cómo la concepción, desarrollo, puesta en marcha y uso de la IA contribuye a reproducir dinámicas de inclusión-exclusión de las/los niños/as y jóvenes. El texto devela las brechas de acceso a las tecnologías y las afectaciones que igualmente pueden sufrir a pesar de no tener acceso a las mismas. Invita a pensar la IA como un ámbito de desarrollo y aplicación tecnológica que se expresa en sistemas algorítmicos que atraviesan casi todos los planos de la vida cotidiana. El libro, según sus editores, pone de relieve, además, «la complejidad de los procesos por los cuales estos sistemas seleccionan, evalúan, infieren y toman decisiones, hace que sea aún más difícil poder comprenderlos y predecir su impacto en términos de oportunidades y desafíos para la sociedad» (p. 15). Es así que, a través de la presentación de distintas experiencias de países latinoamericanos, de casos de estudios y producciones con diversas perspectivas, se propone la reflexión sobre las oportunidades y desafíos que tiene la IA para el bienestar de las y los jóvenes en la región.

La primera sección, «¿Inteligencia artificial, qué es y qué no es?», introduce a lectores que se inician en el tema en los elementos claves que permiten reconocer lo que es o no la IA. De esta manera, Sánchez, editora de sesión, conceptualiza la IA como aquella demostrada por máquinas, en contraposición a la humana, que «incluye tareas como la planificación, la comprensión del lenguaje, el reconocimiento de objetos y sonidos, la resolución de problemas y el aprendizaje a través de la experiencia» (p. 21). Además, puntualiza que existen dos categorías de IA: la general (que puede poseer todas las características de la inteligencia humana, por ejemplo, robots de Boston 
Dynamics) y la estrecha (aquella donde las máquinas solo pueden realizar de forma excelente una sola tarea, por ejemplo, reconocimiento facial, de texto, o de imágenes, etc.). En este apartado, compuesto por tres artículos de Chile, Brasil y México, las/os autores/as abordan definiciones diversas de IA, la historia de esta tecnología, los mitos sobre lo que no es, aclarando que muchos de estos imaginarios se construyen fundamentalmente por libros, filmes y medios de comunicación. Además, invita a prepararse como sociedad para convivir con esta tecnología, sus riesgos, las oportunidades y desafíos que tienen para las juventudes, así como algunas aplicaciones y sistemas de IA enfocados en las y los jóvenes, y los imaginarios que se construyen en torno a esta tecnología.

La segunda sección, «Inteligencia artificial y dinámicas de inclusión/exclusión de las juventudes», compuesta por cinco textos de Colombia, Costa Rica, Argentina y Chile, reflexiona sobre el papel e impacto que las infraestructuras tecnológicas condicionan las relaciones sociales de las y los jóvenes con acceso y sin acceso a ellas. Este apartado aborda de forma crítica cómo las infraestructuras tecnológicas que se encuentran en manos de unas pocas empresas privadas y espacialmente localizadas (Estados Unidos y China principalmente) deben entenderse en estrecha relación con los cambios de sus usuarios y la sociedad. Brossi y Dodds plantean que «sería un grave error descuidar las infraestructuras tecnológicas en la discusión sobre el desarrollo político y cultural de los usuarios» (p. 64). No obstante, a pesar del abordaje crítico relacionado con la inclusión/exclusión presente en los accesos a la IA, se destacan los grandes aportes que esta tecnología realiza a la salud y a la educación. Se reconocen también los desafíos a los que nos enfrentamos para no reproducir las prácticas excluyentes y discriminatorias en estos espacios. Un capítulo especialmente importante en este apartado es el de Rocha y Guío. A partir de su trabajo y experiencia en Colombia realizan una propuesta innovadora para la región, proponiendo medidas para que la IA y las instituciones que las diseñan y ponen en marcha respeten los derechos de las y los niños/as, adolescentes y jóvenes. Enfatizan en la importancia de garantizar el interés superior de los niñas, niñas y adolescentes, exigiendo que cualquier política, lineamiento o aplicación de IA tenga que poner los derechos de estos, no solo como condición ética sino como regulación para proteger sus datos, relevando la importancia de promover procedimientos e instrumentos legales y regulatorios que ofrezcan esta garantía. Además, en esta sección resultan especialmente interesante dos casos de estudio por autores/as chilenos sobre IA presentes en algoritmos de plataformas altamente utilizadas por las y los jóvenes. Uno es el caso de Instagram, donde el diseño de interfaz propicia ciertos modos discursivos 
de mostrarse y actuar que no se corresponden necesariamente con la pertenencia a una estructura social determinada, generando cierta homogenización y aspiración para obtener likes; distanciando y excluyendo por otra parte aquellas otras realidades y formas de mostrarse. El otro caso propone reflexionar cómo desde la programación y narraciones de los videojuegos se pueden subvertir prácticas de exclusión social de las y los jóvenes en Latinoamérica. Para cerrar este importante apartado, también es destacable el texto de Bonilla y Crovo de Argentina, sobre la problemática de los usos y estrategias de búsqueda de información en internet, llamando la atención sobre el impacto de los algoritmos en las y los jóvenes que no reconocen la existencia de estos en internet y no son capaces de diferenciar los contenidos que consumen críticamente, quedando fuera de una gran cantidad de posibilidades por no tener estas competencias. Estos autores postulan explícitamente que el mundo digital reproduce las desigualdades del mundo análogo, en parte por el papel que juegan los algoritmos de IA en internet.

La tercera sección, focalizada en «Jóvenes, inteligencia artificial y educación», está compuesta por cuatro artículos de autores/as de Chile, México y Brasil, y da cuenta de los principios de la alfabetización digital y las nuevas habilidades y construcciones del conocimiento que surge con el uso y apropiación de las tecnologías. Es presentada por Lombana y Passeron, quienes expresan cómo la IA ha estado presente en distintas iniciativas y aplicaciones en educación y aprendizaje desde la década del noventa, con experiencias probadas y buenos resultados hasta el día de hoy. Se refleja, además, una visión crítica sobre el papel de la IA en este ámbito y, aunque se reconoce que en la educación desde sus inicios ha hecho innumerables promesas como la «democratización del conocimiento, inclusión educativa y de mejora en los procesos de aprendizaje en la escuela, la universidad y el hogar» (p. 123), para mejorar la calidad y la disminución de las brechas de acceso, aún son muchos los desafíos que faltan por lograr en la región. En el trabajo de Chile se destaca la relevancia de conocer y educar en el pensamiento computacional como una estrategia eficaz para disminuir las desigualdades. Persiguiendo un objetivo similar y dando cuenta sobre la situación socioeconómica de Brasil, usando los datos de Kids Online Brasil $^{4}$, otros/as autores/as demuestran cómo las desigualdades sociales se expresan en el desarrollo de habilidades digitales en niños/as y adolescentes;

${ }^{4}$ Kids Online Latinoamérica es una red de investigación que se conforma desde Global Kids Online, y la red EU Kids Online de Europa, que estudia y compara mundialmente datos sobre los derechos, habilidades, oportunidades y riesgos de la infancia en la era digital. 
mientras que, en el otro artículo de ese país, se analiza la importancia de la lectura online para las y los jóvenes por su capacidad para promover la colaboración, la distribución e incentivar la participación. Para cerrar, desde México se presenta cómo se utiliza la IA en un sistema inteligente de tutoría de la plataforma del bachillerato en línea de la Universidad Nacional Autónoma de México (UNAM), demostrando cómo se puede acceder a aprendizajes personalizados y automatización de procesos pedagógicos con esta tecnología.

La cuarta sección, titulada «Bienestar, seguridad y privacidad», desarrolla un tema que, a pesar de estar ampliamente abordado, todavía no cuenta con conciencia ni educación suficiente. Cada vez más se interactúa con algoritmos de sistemas y plataformas; y la Internet de las Cosas (IoT) —objetos cotidianos interconectados a internet- es más frecuente en hogares, escuelas y centros de trabajo. Todos estos algoritmos constantemente recolectan datos de las y los usuarios, y en América Latina no todos los países tienen reguladas leyes para proteger la privacidad. En muchos casos se deja el peso de la responsabilidad individual en las y los propios jóvenes, bajo el supuesto ético de que deben conocer las políticas de privacidad de cada uno de los sistemas que utilizan, sin abordarlo desde la responsabilidad social que tienen los productores de estos sistemas. Se hace un llamado de atención, pues los servicios de IA y sus políticas de seguridad y privacidad se orientan al mundo adulto — que tampoco conoce mucho al respecto-, lo que esto implica que no se reconoce explícitamente el riesgo que para las y los jóvenes se divisa en ese escenario. De esta manera, los artículos de esta sección abordan el impacto que la IA puede comprometer en la democracia del país, las burbujas de (des)información a la que se enfrentan y el juicio crítico en la búsqueda de contenido en la red, así como los modelos de gobernanza basados en sistemas autónomos, o los modelos de juguetes conectados con control parental, sus beneficios y desafíos. Todas estas reflexiones en torno a una mejor convivencia humana para el bienestar y protección de las y los niños/as y jóvenes son el foco de esta sección, compuesta por cinco textos, todos escritos por autores/as brasileños/as. Esto, si bien demuestra lo avanzado de las reflexiones en ese país, desbalancea, en mi opinión, el intento que el libro había realizado hasta el momento de mostrar distintas realidades. Además, me genera muchas interrogantes e incertidumbres sobre cuánto nos falta en el resto de los países latinoamericanos para cuidar y proteger la seguridad, el bienestar y privacidad de niños/as y jóvenes.

Por último, la quinta sección, «Narrativas transmedia», compuesta por seis artículos que representan estudios y reflexiones de Argentina, Brasil, 
Colombia y su texto final de España, analiza cómo los algoritmos de IA y los datos, comportamientos y huellas digitales que recopilan aportan a «la implementación, los usos y las oportunidades que ofrecen los sistemas de IA para las narrativas transmedia» (p. 223). En este apartado se discute sobre cómo las máquinas pueden aprender a partir de la IA y los datos que todos/as aportamos cuando autorizamos a sus algoritmos - al aceptar los términos y condiciones de los sistemas - que los integren a sus bases de datos y mecanismos de aprendizaje. Es así que se reflexiona sobre cultura digital, el caso de Netflix, un asistente de voz, las narraciones con imágenes en Instagram y cómo el algoritmo está mediando todo el tiempo en las narrativas interactivas que hacemos en diferentes plataformas. Resulta interesante el texto de Argentina de Bron sobre el uso de la IA y Big Data por Netflix, para enriquecer la experiencia de usuario/as y recomendar el consumo de otros materiales en función de la compatibilidad que tienen los distintos elementos de su catálogo con aquellos materiales que se han visualizado y puntuado positivamente por las y los usuarios/as. Además, se reconoce que en este caso se combinan estrategias de IA con otras tecnologías como Big Data, y experimentos fuera de la red, observación y uso en general del método científico para la toma de decisiones. El autor apunta a la integración de la IA con otros métodos y la importancia de la investigación social para tener mejores resultados. Por su parte, el artículo de Castro de Argentina reflexiona sobre el lugar de las Stories de Instagram que se conforman con diferentes recursos narrativos y que pueden coexistir en distintas plataformas por 24 horas, utilizándose como maneras de expresión de identidad y construcción de socialidades juveniles. Como refiere el autor, «esta forma de consumir y transitar la web construye nuevos sujetos, nuevas subjetividades en los habitantes y productores de narrativas digitales» (p. c267). El texto de Colombia, por su parte, muestra el caso de investigación, diseño y producción de un asistente de voz vinculado a la esfera de las artes, las potencialidades de la IA para recrear narrativas y la obra de autores relevantes de la cultura, de forma dinámica y dirigida a las y los jóvenes como «estrategias transmedias para la apropiación de archivos culturales» (p. 259). Esto, unido al foco del resto de los artículos que tienen en común las narrativas trasmedias y su rol en la cultura digital soportados en algoritmos de IA, permite comprender el desarrollo de esta tecnología en la esfera comunicativa, analizando cómo influye en la forma de narrar historias, en particular por las y los jóvenes que las utilizan.

Tras la lectura detallada del texto, destaco ampliamente las potencialidades de este libro y su capacidad innovadora para posicionar un problema de gran relevancia para América Latina. Articular cinco grandes 
temáticas relacionadas con la IA y construir en torno a ellas reflexiones potentes con una amplia variedad epistemológica, teórica y metodológica, con artículos de autores/as destacados/as en la problemática en la región, es sin dudas su mayor aporte. Cabe en mi opinión señalar algunos puntos que pudieran ser mejorados para futuras ediciones o continuidades de este texto.

Desde una dimensión epistemológica, considero que sería necesario construir con el mismo nivel de profundidad que se trabaja la categoría IA, una discusión transversal sobre lo que se entiende por juventudes, jóvenes, niños/as $y$ adolescentes, para dar cuenta desde qué lugares y saberes se configuran estas categorías y qué supuestos, retos y aproximaciones construyen los conocimientos asociados a las mismas. Las y los jóvenes como categoría, en algunos casos se asume acríticamente, utilizándose para nombrar a sujetos/as de estudios o públicos objetivos de propuestas. En otros se remite a rangos de edades y etapas del desarrollo, justificando ciertas prácticas mediáticas como propias de la edad. En este sentido, no se observa un desarrollo crítico o sistemático de la categoría, invisibilizando en ocasiones el rol protagónico, de producción de contenidos y habilidades que pueden desplegar en sus prácticas digitales. Algo similar sucede con la categoría bienestar de las juventudes, que si bien se enuncia en varios artículos y se discute destacando que parte del bienestar es tener oportunidades de inclusión y no reproducir en lo digital las brechas, desigualdades, discriminaciones, etc., debería quedar en mi opinión mayormente trabajada.

Por último, considero que hubiese sido de interés transparentar más el posicionamiento político de la propuesta. Es decir, qué conocimientos y prácticas contribuyen a legitimar y cuáles a subvertir con estos aportes y reflexiones, así como interpelar más agudamente a las transnacionales dueñas de la mayoría de los algoritmos de IA, a las políticas públicas de los gobiernos de la región, a instituciones concretas, etc. Dar cuenta del compromiso político que entraña el texto es clave para alcanzar el bienestar de las juventudes y evitar que se continúen reproduciendo las desigualdades sociales análogas en las prácticas digitales.

Finalmente, el libro constituye sin dudas, un texto de referencia obligatoria sobre la temática en la actualidad. Nos ofrece un espacio de aprendizaje importante sobre la problemática de la IA y el bienestar de las juventudes en América Latina, que pasa necesariamente por mayores niveles de acceso e inclusión, por políticas de privacidad y seguridad de sus derechos, por mayores oportunidades en la educación, el trabajo, la salud; mayor compromiso 
político de las instituciones, de la industria mediática, los gobiernos, empresarios/as, programadores/as y todos/as aquellos que inciden en la toma de decisión de políticas de IA. Sus reflexiones constituyen una gran apuesta regional para el bienestar y los aprendizajes cotidianos que integran las temáticas de Juventudes e Inteligencia Artificial. 